\title{
Clinical significance of cough and wheeze in the diagnosis of asthma
}

Liverpool School of Tropical Medicine, University of Liverpool Y J Kelly

B J Brabin

P J M Milligan

Sefton Health

Authority

J Reid

Royal Liverpool Children's Hospital, NHS Trust, Alder Hey D Heaf

Aintree Chest Centre, Fazakerley Hospital, Liverpool M G Pearson

Correspondence to: Dr B J Brabin, Liverpool School of Tropical Medicine, Pembroke Place, Liverpool L3 5QA.

Accepted 20 August 1996

Yvonne J Kelly, Bernard J Brabin, Paul J M Milligan, John A Reid, David Heaf, Michael G Pearson

\begin{abstract}
Objectives-(1) To determine the prevalence of cough, wheeze, and breathlessness, both as single symptoms and in combination, in primary schoolchildren and their relation to doctor diagnosed asthma. (2) To identify in areas with different levels of dust pollution whether questionnaire reported 'cough alone' (without wheeze or breathlessness) had similar risk factors to the questionnaire reported triad of 'cough, wheeze, and breathlessness'.

Subjects and methods-Two cross sectional community surveys of primary schoolchildren (5-11 years) were performed in 1991 and 1993. Parent completed questionnaires related to socioeconomic and respiratory factors were distributed through 15 schools in three areas of Merseyside, one of which had a relatively high level of dust pollution. Data were analysed to determine the prevalence of different respiratory symptom patterns. Univariate and multiple logistic regressions were used to investigate the associations between respiratory symptom profiles and potential risk factors.
\end{abstract}

Results-The proportions of completed questionnaires that were returned were similarly high in both surveys, $92 \%$ in 1991 (1872 of 2035) and 87\% in 1993 (3746 of 4288). The proportions of children with different respiratory symptom patterns were similar in the two surveys: in 1991, asymptomatic children $70.1 \%$ (1109 of 1583 ), those with cough alone $8.9 \%$ (141 of 1583), and children with the symptom triad of cough, wheeze, and breathlessness $8.3 \%$ (132 of 1583); the figures for 1993 were $69.5 \%$ (2144 of 3083), 9.2\% (284 of $3083)$, and $7.3 \%$ (224 of 3083) respectively. The prevalence of doctor diagnosed asthma increased from $17.4 \%$ in 1991 to $22.1 \%$ in 1993. The symptom of cough alone was associated with going to school in an area of increased air pollution. The symptom triad of cough, wheeze, and breathlessness was associated with reported allergies, familial history of atopy and preterm birth. In 1991, of children with the symptom of cough alone one in eight were diagnosed asthmatic; twice as many doctors made the diagnosis on this basis in 1993.
Conclusion-The respiratory symptom of cough alone and cough, wheeze, and breathlessness represent clinical responses to different specific risk factors. Cough alone was associated with the environmental factors of school in the dust exposed zone and dampness in the home, whereas cough, wheeze, and breathlessness related to allergic history and preterm birth, and may be the best surrogate of asthma. Diagnosis of asthma on the basis of cough alone partly explains the increased prevalence of doctor diagnosed asthma, especially in dust polluted areas. (Arch Dis Child 1996;75:489-493)

Keywords: asthma diagnosis, cough, wheeze, breathlessness.

Many studies have reported the prevalence of asthma and of respiratory symptoms in children. ${ }^{1-5}$ However, it is difficult to compare the results of different prevalence surveys because study populations have different socioeconomic profiles, environmental risk factors vary with time and between different areas, and the criteria used to define asthma differ. The pattern of respiratory symptoms can vary depending on the magnitude of specific risk factors in the area surveyed. It is necessary to distinguish which symptoms are associated with which risk factors in order to determine which group(s) of symptoms is/are the best surrogate of asthma and therefore estimate the true prevalence of asthma in groups of children with different respiratory symptom patterns.

We have re-examined questionnaire reported data from two cross sectional surveys performed in 1991 and 1993 to assess the possible impact of a dust pollution source on the respiratory health of primary schoolchildren on Merseyside. We previously reported in this population a $60 \%$ greater prevalence of excess cough (without wheeze and without breathlessness) in primary schoolchildren living in an area of increased dust pollution compared with other areas. ${ }^{6}$ We were uncertain whether this increased reporting of cough alone represented an increase in asthma or whether it was a nonasthmatic response to increased levels of inhaled dust. We hypothesised that the symptom triad of cough with wheeze and breathlessness was likely to represent current symptomatic asthma and also examined questionnaire reported 'ever diagnosed asthma' which is 
Table 1 General description of children for both surveys

\begin{tabular}{|c|c|c|}
\hline & $\begin{array}{l}1991 \\
(n=1872)\end{array}$ & $\begin{array}{l}1993 \\
(n=3746)\end{array}$ \\
\hline Mean age (years) (SD) & $7.09(2.0)$ & $7.15(2.0)$ \\
\hline Sex (boy) (\%) & 51.0 & 50.2 \\
\hline Doctor diagnosed asthma (\%) & 17.4 & $22.1^{\star \star \star}$ \\
\hline $\begin{array}{l}\% \text { Living in the area of increased } \\
\text { air pollution }\end{array}$ & 25.9 & 25.0 \\
\hline$\%$ With wheezing & 20.6 & 21.3 \\
\hline$\%$ With breathlessness & 12.8 & 12.7 \\
\hline$\%$ With cough & 22.8 & 23.3 \\
\hline
\end{tabular}

Wheezing: severe attack of wheezing at any time. Breathlessness severe attack of breathlessness at any time. Cough: excess cough in the previous 12 months.

$\star \star \star \mathrm{p}<0.001$, compared with 1991 . For other variables there was no significant difference between 1991 and 1993.

Table 2 Comparison of the prevalence (\%) of respiratory symptom profiles in 1991 and 1993

\begin{tabular}{lll}
\hline & $1991(n=1583) *$ & $1993(n=3083) *$ \\
\hline C-W-B- & 70.1 & 69.5 \\
C+W-B- & 8.9 & 9.2 \\
C+W+B+ & 8.3 & 7.3 \\
C+W+B- & 4.7 & 4.7 \\
C-W+B- & 4.1 & 5.0 \\
C-W+B+ & 1.5 & 1.8 \\
C+W-B+ & 1.7 & 1.1 \\
C-W-B+ & 0.7 & 1.3
\end{tabular}

* Number of questionnaires returned with responses for all respiratory variables. $\mathrm{C}=$ excess cough in the previous 12 months; $\mathrm{B}=$ severe attack of breathlessness at any time; $\mathrm{W}=$ severe attack of wheezing at any time; + or - indicates the presence or absence of a symptom. The symptom patterns of cough alone $(\mathrm{C}+\mathrm{W}-\mathrm{B}-)$ and cough, wheeze, and breathlessness $(\mathrm{C}+\mathrm{W}+\mathrm{B}+)$ are more common than one would expect if the symptoms were independent of each other. $\log$ linear analysis shows that there is a strong positive association between wheeze and breathlessness $\left(\chi^{2}=443, p<0.001\right)$. There is also a positive association between cough and wheeze $\left(\chi^{2}=197, \mathrm{p}<0.001\right)$ and between cough and breathlessness $\left(\chi^{2}=104, \mathrm{p}<0.001\right)$.

often used as a marker of asthma in prevalence studies.

In this paper our objectives were: (1) to determine the prevalence of cough, wheeze, and breathlessness either singly or in combination, (2) to identify whether questionnaire reported cough alone has similar risk factors to the questionnaire reported triad of cough, wheeze, and breathlessness, and (3) to compare the prevalence of doctor diagnosed asthma in children with different symptom patterns.

\section{Subjects and methods \\ DESIGN}

Two cross sectional community based surveys of primary schoolchildren (aged 5-11 years) were performed in 1991 and 1993 in five schools in each of three separate areas in Merseyside. In 1991 every second child on the class register was chosen for the survey (2035), and

Table 3 Proportions of different symptom combinations for children with doctor diagnosed asthma

\begin{tabular}{|c|c|c|c|}
\hline & $\begin{array}{l}1991 \\
(n=237)\end{array}$ & $\begin{array}{l}1993 \\
(n=533)\end{array}$ & $\begin{array}{l}\text { Significance } \\
\text { level } \\
\text { ( } p \text { value) }\end{array}$ \\
\hline Cough, wheeze, and breathlessness $(\mathrm{C}+\mathrm{W}+\mathrm{B}+)$ & 45.6 & 37.7 & 0.05 \\
\hline $\begin{array}{l}\text { Cough or breathlessness with wheeze }(\mathrm{C}+\mathrm{B}-\mathrm{W}+\text { or } \\
\mathrm{C}-\mathrm{B}+\mathrm{W}+)\end{array}$ & 30.7 & 32.5 & 0.71 \\
\hline $\begin{array}{l}\text { Cough and/or breathlessness without wheeze }(\mathrm{C}+\mathrm{B}+\mathrm{W}-\text { or } \\
\mathrm{C}+\mathrm{B}-\mathrm{W}-\text { or } \mathrm{C}-\mathrm{B}+\mathrm{W}-)\end{array}$ & 23.7 & 29.8 & 0.09 \\
\hline
\end{tabular}

$\mathrm{C}=$ excess cough in the previous 12 months; $\mathrm{B}=$ severe attack of breathlessness at any time; $\mathrm{W}=$ severe attack of wheezing at any time; + or - indicates the presence or absence of a symptom. in 1993 all children in each school were surveyed (4288).

\section{QUESTIONNAIRE}

The questionnaire was a modified version of that designed by Clifford et $a l^{1}$ and has been fully described elsewhere. ${ }^{6}$ Class teachers distributed and collected parent completed questionnaires which asked questions about parental smoking patterns, and socioeconomic and respiratory variables. Cough, wheeze, and breathlessness were assessed by the questions, 'has your child ever seemed to cough more (or get more coughs) compared to other children?'; 'has your child ever had wheezing (by wheezing I mean noisy breathing with a whistling sound coming from the chest or throat)?'; 'has your child ever been unexpectedly breathless at rest or more breathless than you would expect after exercise (by breathless I mean out of breath or puffed)?' The symptom triad of cough, wheeze, and breathlessness was deduced from positive responses to all three questions.

\section{STATISTICAL METHODS}

Two types of analysis were performed. Univariate analysis stratified for single risk factors and multiple logistic regression analysis were used to quantify risk factors associated with respiratory symptom profiles.

\section{Results}

The proportions of questionnaires returned were similarly high in both surveys, 1872 of $2035(92 \%)$ in 1991 and 3746 of $4288(87 \%)$ in 1993. Table 1 gives a general description of the study population. More children were diagnosed asthmatic by a doctor in 1993 but there were no differences in the overall prevalence of symptoms between the surveys (table 1).

The proportion of children with no symptoms, with the single symptom of cough, or with cough, wheeze, and breathlessness in combination were also similar in the two surveys (table 2).

In 1993 children with doctor diagnosed asthma were less likely to have the symptom triad of cough, wheeze, and breathlessness $(37.7 \%$ v $45.6 \%)$, and more likely to have been labelled as asthmatic without ever having wheezed (29.8\% v 23.7\%) (table 3).

\section{UNIVARIATE STRATIFIED ANALYSIS}

A comparison of socioeconomic and maternal factors in 1991 and 1993 for asymptomatic children and those with cough alone and cough, wheeze, and breathlessness is shown in table 4. Univariate analysis showed that respiratory symptoms were significantly associated with renting rather than owning a property $(p<0.05)$ and with the reported presence of dampness in the home $(p<0.01)$, but not with the presence of smokers in the home or with having been breast fed. The symptom triad of cough, wheeze, and breathlessness was significantly associated with having been born prematurely $(\mathrm{p}<0.01)$. 
Table 4 Frequency of socioeconomic and maternal variables (\%) for children with different respiratory symptom profiles

\begin{tabular}{llll}
\hline \multicolumn{4}{c}{ Respiratory symptom profile } \\
\cline { 2 - 4 } & $\begin{array}{l}\text { Asymptomatic } \\
(n=1109)\end{array}$ & $\begin{array}{l}\text { Cough } \\
(n=141)\end{array}$ & $\begin{array}{l}\text { Cough, wheeze, breathlessness } \\
(n=132)\end{array}$ \\
\hline 1991 & & & \\
Rented accommodation & 41.1 & 49.3 & $59.7^{\star \star \star}$ \\
Damp home & 12.0 & $22.5^{\star \star}$ & $31.4^{\star \star \star}$ \\
Smoker(s) in household & 58.4 & 66.4 & 65.0 \\
Preterm birth & 12.5 & 13.7 & $26.0^{\star \star \star}$ \\
Not breast fed & 68.2 & 66.2 & 67.9 \\
& & & \\
1993 & $(n=2144)$ & $(n=284)$ & $(n=224)$ \\
Rented accommodation & 42.9 & $54.7^{\star \star \star}$ & $51.6^{\star}$ \\
Damp home & 14.0 & $27.7^{\star \star \star}$ & $30.5^{\star \star \star}$ \\
Smoker(s) in household & 58.0 & 60.6 & 61.2 \\
Mother smoked during & 36.0 & 34.3 & 35.1 \\
pregnancy & & 11.7 & $19.4^{\star \star}$ \\
Preterm birth & 11.8 & 73.5 & 65.2 \\
Not breast fed & 68.1 & & \\
\hline
\end{tabular}

${ }^{\star} \mathrm{p}<0.05,{ }^{\star \star} \mathrm{p}<0.01,{ }^{\star \star \star} \mathrm{p}<0.001$, compared with asymptomatic children.

Table 5 Health parameters (\%) in 1991 and 1993 for children with different respiratory profiles

\begin{tabular}{|c|c|c|c|}
\hline & \multicolumn{3}{|c|}{ Respiratory symptom profile } \\
\hline & $\begin{array}{l}\text { Asymptomatic } \\
(n=1109)\end{array}$ & $\begin{array}{l}\text { Cough } \\
(n=141)\end{array}$ & $\begin{array}{l}\text { Cough, wheeze, } \\
\text { breathlessness } \\
(n=132)\end{array}$ \\
\hline \multicolumn{4}{|l|}{1991} \\
\hline Doctor diagnosed asthma & 2.1 & 10.0 & 83.1 \\
\hline Allegies (hay fever, eczema) & 8.7 & 13.3 & 47.3 \\
\hline Prescribed medicines $\dagger$ & 4.4 & 14.9 & 61.8 \\
\hline $\begin{array}{l}\text { Absent from school due to respiratory } \\
\text { symptoms for }>6 \text { days/year }\end{array}$ & 0.9 & 5.7 & 39.0 \\
\hline $\begin{array}{l}\text { Ever admitted to hospital for respiratory } \\
\text { symptoms }\end{array}$ & 3.0 & 25.0 & 61.0 \\
\hline 1993 & $(n=2144)$ & $(n=284)$ & $(n=224)$ \\
\hline Doctor diagnosed asthma & 3.0 & $22.6^{\star}$ & 89.9 \\
\hline Allegies (hay fever, eczema) & $12.9^{\star}$ & 18.8 & $61.0^{\star}$ \\
\hline Prescribed medicinest & 5.2 & 22.9 & $75.1^{\star}$ \\
\hline $\begin{array}{l}\text { Absent from school due to respiratory } \\
\text { symptoms for }>6 \text { days/year }\end{array}$ & 1.5 & 4.6 & 36.8 \\
\hline $\begin{array}{l}\text { Ever admitted to hospital for respiratory } \\
\text { symptoms }\end{array}$ & 4.1 & 25.6 & 61.4 \\
\hline
\end{tabular}

In both surveys asymptomatic children were less likely to have doctor diagnosed asthma, allergies, medicines prescribed, admissions to hospital for respiratory symptoms, absenteeism from school (for more than six days) due to respiratory symptoms (all $\mathrm{p}<0.01$ ), compared with children with cough alone or cough, wheeze, and breathlessness (table 5). Children with cough alone had a lower prevalence of each of these ill health indicators when compared with children with cough, wheeze, and breathlessness.
In 1993 the children with cough alone were more likely to have been diagnosed as asthmatic by a doctor $(\mathrm{p}<0.05)$ and to report problems with allergies. Significantly more children with the symptom triad received prescribed medicines in $1993(\mathrm{p}<0.05)$, although $25 \%$ were reported to be receiving no medication. In $1991,2.1 \%$ (23 of 1109 ) and in 1993, 3.0\% (63 of 2144) of asymptomatic children had a history of doctor diagnosed asthma. Although none of these children had current symptoms, $52 \%$ in 1991 (12 of 23) and 38\% in 1993 (24 of 63) had a cough at some time in life which had been diagnosed as asthma. Reported diagnosis of asthma in other asymptomatic children remains unexplained.

REGRESSION ANALYSIS

Adjusted odds ratios for risk factors were calculated for respiratory symptom profiles by logistic regression in order to control for multiple confounding factors (table 6). Maternal asthma, allergies, and other health problems were strongly associated with cough, wheeze, and breathlessness. Preterm birth and paternal asthma were associated with cough and wheeze. The risk of cough and wheeze decreased with age (more steeply for cough). Of the other risk factors, some were associated with wheeze and some only with cough. Children with environmental risk factors such as going to school in the area of increased dust pollution, dampness in the home and rented accommodation were more likely to have cough alone.

\section{Discussion}

PREVALENCE OF RESPIRATORY SYMPTOM PROFILES Questionnaires are often used in respiratory health surveys, and data collected in this way have been shown to be reproducible. ${ }^{78}$ Confidence that the information collected is valid is dependent upon response rates, which in this study compared favourably with other reports. $^{1-59}$

The two surveys were performed in parallel in the same areas and in the same months (October to December), avoiding variations due to seasonal influences. The prevalence of wheezing, cough, and breathlessness is comparable with previous reports. ${ }^{4510}$ The cumulative prevalence of doctor diagnosed asthma is higher than reported elsewhere, although this may be confounded partly by the low social class of the three areas in this study.

Table 6 Logistic regression models for cough, wheeze, and breathlessness for 1993 data; results are odds ratio (95\% confidence interval)

\begin{tabular}{llll}
\hline & Cough & Wheeze & Breathlessness \\
\hline Child has allergies & $3.29(2.50$ to 4.33$)$ & $4.47(3.36$ to 5.94$)$ & $5.26(3.79$ to 7.29$)$ \\
Maternal asthma & $1.67(1.65$ to 2.43$)$ & $2.71(1.87$ to 3.93$)$ & $2.87(1.91$ to 4.33$)$ \\
Child has other health problems & $1.91(1.44$ to 2.53$)$ & $1.82(1.34$ to 2.46$)$ & $1.65(1.10$ to 2.46$)$ \\
Age in years & $0.83(0.78$ to 0.88$)$ & $0.92(0.87$ to 0.97$)$ & $0.99(0.93$ to 1.06$)$ \\
Preterm birth & $1.65(1.24$ to 2.20$)$ & $1.46(1.08$ to 2.00$)$ & $1.38(0.95$ to 1.99$)$ \\
Paternal asthma & $1.43(0.96$ to 2.12$)$ & $1.71(1.13$ to 2.58$)$ & $1.25(0.75$ to 2.08$)$ \\
Sex (boy) & $0.83(0.67$ to 1.03$)$ & $0.79(0.63$ to 1.00$)$ & $0.91(0.69$ to 1.19$)$ \\
Father works in dusty environment & $1.15(0.90$ to 1.48$)$ & $1.64(1.27$ to 2.12$)$ & $1.13(0.82$ to 1.55$)$ \\
Unemployed mother & $1.31(1.01$ to 1.68$)$ & $1.28(0.97$ to 1.68$)$ & $1.11(0.80$ to 1.55$)$ \\
School in area of increased dust pollution & $1.46(1.14$ to 1.87$)$ & $1.22(0.93$ to 1.60$)$ & $1.28(0.93$ to 1.78$)$ \\
Damp home & $1.56(1.19$ to 2.04$)$ & $1.24(0.92$ to 1.62$)$ & $1.25(0.88$ to 1.78$)$ \\
Rented accommodation & $1.32(1.08$ to 1.60$)$ & $1.08(0.83$ to 1.39$)$ & $0.88(0.64$ to 1.21$)$ \\
\hline
\end{tabular}


School absenteeism for respiratory symptoms is a useful indicator of respiratory morbidity. ${ }^{3611}$ Absences from school (for more than six days) due to respiratory symptoms and admissions to hospital for the same reason declined slightly between 1991 and 1993.

RISK FACTORS FOR SYMPTOM PROFILES

Reports of the effects of parental smoking on lung function and respiratory health of children are inconsistent. There are reports of strong associations of childhood respiratory symptoms with passive smoking especially in susceptible children, ${ }^{12}{ }^{13}$ and suggestions that the findings may be dependent on the amount of contact between parent and child, ${ }^{14}$ or whether the mother smoked during pregnancy. ${ }^{15}{ }^{16} \mathrm{We}$ have been unable to replicate these findings in 1993 despite the large numbers in the study and controlling directly for many social class and environmental factors. Neither was there an association between having been breast fed and later childhood respiratory symptoms, which is in agreement with other recent reports. ${ }^{17}{ }^{18}$ Reported wheeze has been shown to be more likely with the reported presence of dampness in the home, ${ }^{19}$ our study supports this. Babies born preterm were more likely to develop the symptom triad during childhood than babies born full term. ${ }^{20}$

There are significant detrimental effects of air pollution on respiratory health. ${ }^{21-24}$ In asthmatic children an increase in the severity, but not the prevalence, of respiratory symptoms has been associated with air pollution. ${ }^{25}$ Other surveys have reported cough as the main respiratory symptom associated with high levels of air pollution. ${ }^{625-29}$

Our earlier report showed that excess cough as a single symptom was associated with particulate air pollution, and the more sophisticated analysis in this paper confirms that observation. However, the single symptom of wheezing and the symptom triad of cough, wheeze, and breathlessness did not correlate with pollution. The symptom triad correlates best with the features of atopy and also with having been born prematurely. The difference in risk profiles between cough alone and the triad of cough, wheeze, and breathlessness are consistent whether the data are analysed by simple univariate comparisons or multiple logistic regression, which suggests that these epidemiological classifications may represent distinct clinical entities. Thus, if a child has cough, wheeze, and breathlessness, then a diagnosis of asthma seems very probable, and conversely the single symptom of excess cough could be a non-specific response to adverse environmental conditions and not represent asthma at all. Such a hypothesis cannot be answered from cross sectional studies alone but there is a further observation that supports it.

Doctor diagnosed asthma was reported in 83 and $90 \%$ of children with the symptom triad in 1991 and 1993 against only 10 and $23 \%$ of those with excess cough only and hardly at all in asymptomatic children. Treatment prescrib- ing follows a similar pattern. Thus doctors appear to have recognised a similar distinction in clinical practice.

Between 1991 and 1993 there was a significant increase in the prevalence of doctor diagnosed asthma and also in the number of children receiving medication for asthma. Since overall symptom prevalence was unchanged, this suggests a change in medical behaviour. The increase in labelling was most marked in those reporting the single symptom 'excess cough', with more than twice as many of these children being diagnosed as asthmatic and, if allowance is made for the non-asthma medication being unchanged, nearly twice as many received asthma therapy. In 1993, one in eight children that doctors had diagnosed as asthmatic had been diagnosed on the basis of the single symptom of cough. Whether these children really have asthma warranting treatment or whether doctors have become more aware of, and aggressive towards, cough as a marker of asthma remains unknown. Possibly doctors use cough together with auscultation of the chest to reach a diagnosis. If the index of asthma in our survey had been 'doctor diagnosis of asthma' we would be reporting an increase in asthma of nearly $5 \%$ over 2 years, which, since overall symptom prevalence was unchanged, would have been misleading.

In conclusion, we hypothesise that the symptom triad of cough, wheeze, and breathlessness occurring in a child may be a better marker of true asthma in epidemiological surveys than relying on either single symptoms or doctor diagnostic patterns. Since asthma prevalence is so dependent on the definition adopted, further studies are needed either to confirm this hypothesis or produce a better version that can be adopted as a standard.

The authors would like to thank school teachers, health visitors, and children without whom these studies would not have been possible. We are grateful for the support of the Asthma Steering possible. We are grateful for the support of the Asthma Steering Committee. We wish to thank Mr Ken Jones of the Medical Illustration Unit, Mrs Wanda Russell and Mr Barry Moody of the Epidemiology and Statistics Unit of the School of Tropical
Medicine for their help. PM is grateful for the support of the
Wellcome Trust. This project was funded by a grant from South Sefton Health Authority and Sefton Metropolitan Borough Council.

1 Clifford RD, Radford M, Howell JB, Holgate ST. Prevalence of respiratory symptoms among 7 and 11 year old schoolchildren and association with asthma. Arch Dis Child 1989;64:1118-25.

2 Ayers JG, Pansari S, Weller PH, et al. A high incidence of asthma and respiratory symptoms in 4-11 year old children. Respir Med 1992;86:403-7.

3 Anderson HR, Butland BK, Strachan DP. Trends in prevalence and severity of childhood asthma. BMF 1994;308: 1600-4.

4 Ninan TK, Russell G. Respiratory symptoms and atopy in Aberdeen schoolchildren: evidence from two surveys 25 years apart. $B M F$ 1992;304:873-5.

5 Luyt DK, Burton PR, Simpson H. Epidemiological study of wheeze, doctor diagnosed asthma, and cough in preschool children in Leicestershire. BMF 1993;306:1386-90.

6 Brabin B, Smith M, Milligan P, Benjamin C, Dunne E, Pearson M. Respiratory morbidity in Merseyside schoolPearson $\mathrm{M}$. Respiratory morbidity in Merseyside schoolchildren exposed to co

7 Brunenkeef B, Groot B, Rijcken B, Hoek G, Steenbekkers A, de Boer A. Reproducibility of childhood respiratory A, de Boer A. Reproducibility of childhood

8 symptom questions. Eur Respir f 1992;5:930-5. Reliability of questionnaire reporting of early childhood health status, family history of respiratory illness and early health status, family history of respiratory illness and early exposure to seco

1994;149:A389

Andrae S, Axelson O, Bjorksten B, Fredrickson M Kjellman NIM. Symptoms of bronchial hyperreactivity and 
asthma in relation to environmental factors. Arch Dis Child 1988;63:473-8.

10 von Mutius E, Fritzsch C, Weiland SK, Roll G, Magnussen $H$. Prevalence of asthma and allergic disorders among children in united Germany: a descriptive comparison. BMF 1992;305:1395-9.

11 Hill RA, Standen PJ, Tattersfield AE. Asthma, wheezing and school absences in primary schools. Arch Dis Child 1989;64:246-51.

12 Duff AL, Pomeranz ES, Geller LE, et al. Risk factors for acute wheezing in infants and children: viruses, passive smoking, and IgE antibodies to inhalant allergens. Pediatrics 1993;92:535-40.

13 Charlton A. Children's coughs and parental smoking. BMF 1984;288:1647-9.

14 Rona RJ, Chinn S. Lung function, respiratory illness, and passive smoking in British primary schoolchildren. Thorax passive smokin

15 Ness LM, Dockery DW, Ware JH, Spengler JD, Ferris BG, Speizer FE. Concentration of indoor particulate matter as a determinant of respiratory health in children. Am $\mathcal{F}$ Epidemiol 1994;139:1088-99.

16 Tager IB, Weis ST, Munoz A, Rosner B, Speizer FE. Longitudinal study of the effects of maternal smoking on pulmonary function in children. $N$ Engl $\mathcal{F} M$ Med 1983;309:699-703.

17 Horwood LJ, Fergussen DM, Shannon FT. Social and familial factors in the development of childhood asthma. Pediatrics 1985;75:859-68.

18 Fergusson DM, Horwood LJ, Shannon FT. Asthma and infant diet. Arch Dis Child 1983;58:48-51.

19 Strachan DP. Damp housing and childhood asthma: validation of reporting of symptoms. $B M F$ 1988;297:1223-6.
20 Kelly YJ, Brabin BJ, Milligan P, Heaf DP, Reid J, Pearson MG. Maternal asthma, premature birth, and the risk of respiratory morbidity in school children in Merseyside. Thorax 1995;50:525-30.

21 Sultz H, Feldman JG, Schlesinger ER, Mosher WE. An effect of continued exposure to air pollution on the incidence of chronic childhood allergic disease. $A m \mathcal{F} P u b$ lic Health 1970;60:891-900.

22 Lunn JE, Knowelden J, Handyside AJ. Patterns of respiratory illness in Sheffield infant schoolchildren. British fournal of Preventive Medicine 1967;21:7-16.

23 Borak M, Leon DA. Air pollution and infant mortality in the Czech Republic 1986-88. Lancet 1992;340:1010-4.

24 Wang JY, Hisuc TR, Chen HI. Bronchial responsiveness in an area of air pollution resulting from wire reclamation. Arch Dis Child 1992;67:488-90.

25 Ware JH, Ferris BG, Dockery DW, Spengler JD, Strom DO Speizer FE. Effects of ambient sulfur oxides and suspended particles on respiratory health of preadolescent children. Am Rev Respir Dis 1986;133:834-42.

26 Sorral HR. Air pollution and respiratory disease in children in Sao Paulo, Brazil. Soc Sci Med 1989;29:959-64.

27 Braun-fahrlander C, Ackerman-Liebrich U, Schwartz J Gnehm HP, Rutishauser M, Wanner HU. Air pollution and respiratory symptoms in pre-school children. Am Rev Respir Dis 1992;145:42-7.

28 Arden Pope C, Dockery DW. Acute health effects of PM pollution on symptomatic and asymptomatic children. $A m$ Rev Respir Dis 1992;145:1123-8.

29 Dockery DW, Speizer FE, Stram DO, Ware JH, Spengler JD, Ferris BG. Effects of inhalable particles on respiratory health in children. Am Rev Respir Dis 1989;139:587-94. 